\title{
Promoting adolescent health: health literacy, self-efficacy and internet use
}

\author{
Dilara Ceylan ${ }^{1 \oplus}$, Feyza Nur Akan Çelen ${ }^{2 \oplus}$, Seçil Özkan²๑, Zehra Aycan ${ }^{3 \oplus}$ \\ ${ }^{1}$ Department of Pediatrics, Akyurt State Hospital, Ankara; ${ }^{2}$ Department of Public Health, Gazi University Faculty of Medicine, Ankara; \\ ${ }^{3}$ Division of Adolescent Medicine, Department of Pediatric Endocrinology, Ankara University Faculty of Medicine, Ankara, Turkey.
}

\begin{abstract}
Background. Adolescents are mostly considered as a healthy population; however, failure to acquire positive health behaviors during this period makes them vulnerable to poor health outcomes and long-term chronic disorders. Health literacy is one of the most influential parameters in promoting adolescent health. This study aimed to determine the level and promoters of health literacy in adolescents, emphasize the importance of internet use, and evaluate the relationship between self-efficacy and health literacy.
\end{abstract}

Methods. A total of 756 adolescents aged 15 and 18 years attending two high schools in socioeconomically different districts in Ankara, Turkey were included in this cross-sectional study. A survey consisting of descriptive questions, a health literacy survey, and a general self-efficacy scale were used to collect data. $\mathrm{p}<0.05$ was considered statistically significant.

Results. Among the adolescents who participated in the study, the level of health literacy was inadequatelimited in $56.1 \%$, sufficient in $30.1 \%$, and excellent in $13.8 \%$. A statistically significant correlation was found between health literacy and general self-efficacy levels ( $\mathrm{r} . .412, \mathrm{p}<0.001)$. There was also a statistically significant difference between the health literacy groups in terms of the education level of the adolescents' mothers, internet use frequency, and self-efficacy level. The multivariate logistic regression analysis revealed that the participants whose mothers had only received primary school education or no formal education, those that were not using the internet regularly, those that did not search health information on the internet, and those with poor self-efficacy levels were more likely to have an inadequate level of health literacy [odds ratio $(\mathrm{OR})=2.6$, 95\% confidence interval $(\mathrm{CI})=1.4-4.9 ; \mathrm{OR}=5.5,95 \% \mathrm{CI}=1.2-25.1 ; \mathrm{OR}=1.7,95 \% \mathrm{CI}=1.1-2.9$; and $\mathrm{OR}=3.7,95 \% \mathrm{CI}=2.6-$ 5.2, respectively].

Conclusions. In this study, it was concluded that the adolescents' health literacy and general self-efficacy levels were related. Furthermore, the health literacy level of the adolescents was associated with internet use and maternal education status.

Key words: health literacy, adolescent, self-efficacy, internet use.

Adolescence is a complex transition period that includes physical growth and the development of secondary sex characteristics, new cognitive skills, and sexual identity. ${ }^{1}$ Adult health behavior patterns are set in this critical period. ${ }^{2}$

$\varangle$ Dilara Ceylan

mddilaradag@gmail.com

Received 19th April 2021, revised 3rd August 2021, accepted 18th August 2021.

The study presented as poster presentation at 7 . Adolescent Health Congress, 22-24 March, 2019, Ankara, Turkey.
Adolescents are considered as the healthy population who do not require special health services or mostly do not have any chronic disease. However, failure to acquire positive health behaviors during this period makes them vulnerable to poor health outcomes and longterm chronic disorders during both adolescence and adulthood. ${ }^{3}$ Furthermore, risky behaviors which frequently begin in adolescence, such as tobacco, alcohol and substance use, risky sexual behaviors, overeating, and lack of physical activity often lead to chronic diseases in adulthood. ${ }^{4,5}$ Promoting adolescent health is 
essential to ensure a healthy life course as an individual and support public health. ${ }^{6}$

Today, health literacy (HL) is one of the most essential and effective parameters for promoting health. HL has a multidimensional construction, and it is defined as a combination of knowledge, motivation, and proficiency that allow people to access, understand, evaluate and use health information in order to improve their health, prevent diseases, and make decisions in everyday life to maintain or improve their health and quality of life. ${ }^{7}$ Adult studies have shown that differences in HL levels are related to increased emergency service visits and hospitalization, less use of preventive healthcare services, poor overall health status in the population over 65 , and higher mortality. ${ }^{8}$ Although several adult studies have been conducted on HL, their results cannot be directly generalized to the pediatric population considering the different characteristics of childhood and especially adolescence. Limited adolescent research suggests that obesity, smoking, alcohol use, and drug abuse are related to low HL levels in adolescents. ${ }^{9,10}$

Although HL plays an essential role in health behavior changes, such behaviors are also influenced by psychosocial factors, such as selfefficacy (SE). ${ }^{11}$ SE refers to an individuals' belief and confidence in their capacity to perform a specific behavior in diverse situations. ${ }^{12}$ High SE indicates more effort being made to attain desirable outcomes despite barriers; therefore, it is one of the crucial components of health promotion behaviors and a determinant for initiating and maintaining positive health behaviors. $^{13}$ Additionally, SE has been exceptional for proper self-management for several chronic health conditions, such as diabetes and asthma. ${ }^{11,14}$ Furthermore, people with higher SE have been found to be exhibit more ambitious behavior to maintain a healthy diet for weight loss. ${ }^{15}$ Lastly, individuals with lower SE and HL are less likely to apply preventative health behaviors. ${ }^{16}$ However, despite these adult studies frequently reporting the relationship between disease-based HL and SE status, there are still a limited number of adolescent studies in this area.

The internet is an essential tool for connecting with friends and one of the primary sources for almost every subject in the life of an adolescent. ${ }^{17}$ Therefore, internet-based health-related information seeking behavior of adolescents is increasingly being studied worldwide. ${ }^{18-20}$ The internet is easy to use, provides the fastest way to reach all types of information, and offers anonymity; therefore, it has been shown that adolescents prefer the internet as a primary source of health-related information rather than traditional health services. ${ }^{21}$ In addition, a previous study showed that more than two-thirds of adolescents accessed healthrelated information on the internet in the USA. ${ }^{22}$ This tendency can guide the design of developmentally relevant interventions that may support healthy lifestyle choices and promote HL among adolescents. ${ }^{23}$

This study aimed to determine the level of HL in adolescents, evaluate the relationship between $\mathrm{SE}$ and HL, and define significant promoters of $\mathrm{HL}$, such as the internet among adolescents.

\section{Material and Methods}

\section{Participants}

The participants consisted of high school students aged 15 years and older because the scales used had been previously tested for reliability and validity for this age group in two socioeconomically different districts in the Urban Poverty Mapping Study ${ }^{24}$ conducted in Ankara, Turkey. The two high schools participating in the study had 1,582 students during the 2017-2018 academic year. The study was designed as cross-sectional. The number of individuals required for the sample of the study was calculated using the following formula: sample size $(\mathrm{n})=[\mathrm{DEFF} \times \mathrm{Np}(1-\mathrm{p})] /[(\mathrm{d} 2 / \mathrm{Z} 21$ $-\alpha / 2 \times(\mathrm{N} 1)+\mathrm{p} \times(1-\mathrm{p})]^{25,26}$ where $\mathrm{n}$ refers to the population size $(1,582), \mathrm{p}$ refers to the 
prevalence of limited HL (0.5), d refers to the absolute precision value (0.3), DEFF refers to the design effect (1), Z1- $\alpha / 2$ was 1.96 , and $p$ was accepted as 0.5 considering that the proportion of $50 \%$ indicates maximum variability. ${ }^{27} \mathrm{An}$ estimated minimum sample size of 638 was obtained using the assumptions given above. The convenience sampling method, one of the non-probability sampling methods, was used since the principals of the schools allocated limited time to administer the data collection tools. Using this method, we initially reached 850 participants, but 94 were excluded from the sample because they did not respond to all the questions in the survey. The final data analysis was performed on the data of 756 participants.

\section{Procedure}

The study started after receiving approval by local ethics committee of Keçiören Research and Training Hospital (approval reference number: 2012-KAEK-15/1606) and obtaining permission from the principals of the participating schools.

The schools sent a consent letter to the parents to inform them about the study objectives and procedures. The parents that provided consent for their children's participation in the study signed and returned this form. The students completed the surveys in the school over approximately 20 minutes in September 2018.

\section{Measures}

The survey consisted of 56 questions to determine sociodemographic characteristics, internet use patterns, health information, HL, and SE.

\section{Sociodemographic information, internet use, and health information}

In this section, information on age, gender, parental education status, and school region was collected. In addition, methods to access healthrelated information (doctors, family, friends, TV, internet, school, and others), internet use frequency, whether health information was accessed using the internet, and most searched health topics on the internet were questioned. As health topics, primary subjects related to adolescent medicine were used, and an open-ended option was provided. Due to the increasing trend toward exercise and sports supplements, these topics were also included as options.

\section{Health literacy}

The HL level was measured using the 'Turkish Health Literacy Survey' (THLS, $\alpha=0.92$ ), which was adapted from the original English version of the 'European Health Literacy Survey' (HLSEUS). THLS comprised 32 items and was rated on a five-point Likert scale to measure the HL level. Total scores were measured and standardized with an index formula between 0 to 50 , with 0 representing the 'worst' and 50 representing the 'best' score. The HL levels were classified as 'inadequate' (0-25), 'problematic' (>25-33), 'sufficient' (>33-42), and 'excellent' (>42-50) as in the HLS-EUS study, and the 'inadequate' and 'problematic' levels were combined to a single level called 'limited HL' (0-33) to identify the vulnerable groups. ${ }^{28}$ In this study, Cronbach's alpha was 0.90 .

\section{Self-efficacy}

SE was measured using the Turkish version of the General Self-Efficacy Scale (GSES) developed by Schwarzer and Jerusalem, which included ten items rated on a four-point Likert scale $(1=$ not at all true; 2 = rather untrue; $3=$ rather true, and $4=$ exactly true). This scale was designed to measure an individual's subjective belief in her/himself in coping with stressful situations. Higher scores in this scale reflect a higher level of SE. ${ }^{29}$ Since there is no cut-off score specified in the literature, we classified the scale scores according to the median score. Thus, the SE levels were categorized as good if the participants scored above the median value and poor if their score was below the median value.

The validity and reliability studies of the Turkish version of the scale were conducted in 2010 with 
693 students at various class levels. According to the results of the exploratory factor analysis, the factor loads of the scale varied from 0.45 to 0.75 . The explained total variance was $47 \%$. The internal consistency of GSES (Cronbach alpha value) was found to be 0.83 . The test-retest reliability of the scale was $\mathrm{r}=0.80, \mathrm{p}<.001 .{ }^{29} \mathrm{In}$ our target sample, the construct validity analysis of the Turkish GSES was also evaluated with the exploratory factor analysis. The total variance explained by the scale was $40.1 \%$, and the factor loads of each item varied between 0.485 and 0.680 . The internal consistency analysis showed that the scale was reliable, with the Cronbach alpha being calculated as 0.83 . The item-total correlation values ranged from 0.377 to 0.571 , with no item having a value below 0.30. As a result of the validity and reliability analyses, it was determined that the 10 -item scale was valid and reliable for our study group.

\section{Data analysis}

Data analysis was conducted with IBM SPSS, v. 23.0 (SPSS Inc., Chicago, IL). The Pearson's chi-squared test was used to compare categorical variables between independent groups in order to examine the differences between the adolescents' HL levels across sociodemographic and health information/ internet use characteristics. The correlation between the SE and HL levels was analyzed using Spearman's correlation coefficient. In order to define the predictors of inadequate $\mathrm{HL}$, the multivariate logistic regression analysis was used. The variable selection method was the 'Enter method', and all the variables were entered in one step. A univariate estimate was performed with the logistic regression analysis, and variables with a significance level of $p<$ 0.05 in the univariate analysis were included in the multivariate logistic regression analysis to determine the association of each independent variable with outcome variables. The crude and adjusted odds ratio (OR) and 95\% confidence interval $(\mathrm{CI})$ values were also obtained. $\mathrm{p}<0.05$ was considered as statistically significant.

\section{Results}

\section{Sample Characteristics}

Sample characteristics are shown in Table I. The sample consisted of 756 students aged 1518 years, and $65.9 \%$ were female. Half of the students' parents had secondary or high school education. As the source of health information, the participants most preferred doctors (72.2\%), followed by the internet (69.1\%). Almost all the participants regularly used the internet, and most $(86.5 \%)$ sought health-related topics via the internet. Table II presents the percentages of most searched topics. Sports, healthy nutrition, acne, losing weight, and short stature were the most popular subjects.

\section{Health Literacy and Self-Efficacy}

Descriptive statistics \{mean \pm standard deviation [median (minimum-maximum) \} for THLS was $32.25 \pm 9.13$ [32.29 (1-50)], and Table III shows the HL levels according to the THLS scores. Over half of the participants had limited HL $(56.1 \%)$, while $30.1 \%$ had sufficient and only $13.8 \%$ had excellent literacy skills. Table IV presents the HL levels by sample characteristics. Age, gender, and school region were not related to the HL level. However, the univariate analysis showed that parental education status, internet use frequency, and accessing health information through the internet resulted in statistically significant differences in the HL level. Accordingly, the adolescents who were using the internet regularly and sought health information on the internet tended to have higher HL levels. Descriptive statistics \{mean \pm standard deviation [median (minimummaximum)\} for SE was $31.05 \pm 5.44$ [31 (10$40)]$. The level of $S E$ was good ( $\geq$ median value) in $57.4 \%(n=434)$ of the participants. Figure 1 shows the results of the Spearman correlation analysis, which indicated a moderate positive correlation (r: .412, $\mathrm{p}<0.001)$ between SE and HL. 
Table I. Sample characteristics.

\begin{tabular}{|c|c|c|}
\hline Variables & $\mathrm{n}$ & $(\%)$ \\
\hline \multicolumn{3}{|l|}{ Age $(n=756)$} \\
\hline 15 & 293 & 38.8 \\
\hline 16 & 232 & 30.7 \\
\hline 17 & 126 & 16.7 \\
\hline 18 & 105 & 13.9 \\
\hline \multicolumn{3}{|l|}{ Gender $(n=756)$} \\
\hline Male & 498 & 34.1 \\
\hline Female & 258 & 65.9 \\
\hline \multicolumn{3}{|l|}{ Maternal education status $(n=756)$} \\
\hline No education or primary school & 283 & 37.4 \\
\hline Secondary or high school & 396 & 52.4 \\
\hline College or university & 77 & 10.2 \\
\hline \multicolumn{3}{|l|}{ Paternal education status $(n=756)$} \\
\hline No education or primary school & 176 & 23.3 \\
\hline Secondary or high School & 443 & 58.6 \\
\hline College/university & 137 & 18.1 \\
\hline \multicolumn{3}{|c|}{$\begin{array}{l}\text { Socioeconomic level of school district } \\
(\mathrm{n}=756)\end{array}$} \\
\hline Low & 252 & 33.3 \\
\hline High & 504 & 66.7 \\
\hline \multicolumn{3}{|l|}{$\begin{array}{l}\text { Methods to access health-related } \\
\text { information }(n=756)^{ \pm}\end{array}$} \\
\hline Family & 381 & 48 \\
\hline Friends & 69 & 8.7 \\
\hline Doctors & 573 & 72.2 \\
\hline Television & 219 & 27.6 \\
\hline Internet & 548 & 69.1 \\
\hline School & 130 & 16.3 \\
\hline Others & 12 & 1.5 \\
\hline \multicolumn{3}{|l|}{ Internet use frequency $(\mathrm{n}=756)$} \\
\hline Everyday & 569 & 75.3 \\
\hline A few days per week & 141 & 18.7 \\
\hline A few days per month & 23 & 3 \\
\hline Never & 23 & 3 \\
\hline
\end{tabular}

Accessing health information through the internet $(n=756)$

\begin{tabular}{lll} 
Yes & 653 & 86.5 \\
No & 102 & 13.5 \\
\hline
\end{tabular}

${ }^{ \pm}$:multiple answers allowed
Table II. Most searched health topics accessed through the internet.

\begin{tabular}{lcc}
\hline Topics $(\mathrm{n}=735)^{ \pm}$ & $\mathrm{n}$ & $(\%)$ \\
\hline Exercise & 443 & 57.5 \\
Diet, nutrition & 429 & 55.7 \\
Acne & 352 & 45.7 \\
Lose weight & 302 & 39.2 \\
Short stature & 193 & 25 \\
Weight gain & 183 & 23.7 \\
Menstrual irregularities & 180 & 23.3 \\
Sports supplements & 156 & 20.2 \\
Depression & 134 & 17.4 \\
Obesity & 81 & 10.5 \\
Vaccination & 72 & 9.3 \\
Hirsutism & 67 & 8.7 \\
Smoking & 61 & 7.9 \\
Sex & 54 & 7 \\
Alcohol & 45 & 5.8 \\
Sexually transmitted diseases & 43 & 5.5 \\
Drug abuse & 27 & 3.5 \\
Pregnancy & 12 & 1.5 \\
Contraception & 6 & 0.7 \\
Others & 39 & 5 \\
\hline
\end{tabular}

${ }^{ \pm}$:multiple answers allowed

Table III. Health literacy level according to the Turkish Health Literacy Scale.

\begin{tabular}{lcc}
\hline Health Literacy Level $(\mathrm{n}=756)$ & $\mathrm{n}$ & $(\%)$ \\
\hline Inadequate $(\leq 25)$ & 155 & 20.5 \\
Problematic $(>25-33)$ & 269 & 35.6 \\
Sufficient $(>33-42)$ & 228 & 30.1 \\
Excellent $(>42-50)$ & 104 & 13.8 \\
\hline
\end{tabular}

\section{Multivariate Test Results}

Table V shows the results of the binary logistic model used to test the association between inadequate HL levels and other variables. In contrast to the univariate analysis, paternal education status was not found to be related to $\mathrm{HL}$ in the binary logistic analysis $(\mathrm{OR}=0.7$; $95 \%$ CI (0.4-1.2); $\mathrm{p}=0.222)$. However, maternal education status was statically significant related to HL. Adolescents whose mothers had received primary school education or 
no formal education were more than twice as likely to have inadequate HL levels than those whose mothers had graduated from college or university $(\mathrm{OR}=2.6$; 95\% CI (1.4-4.9); $\mathrm{p}=0.004)$. In addition, the adolescents who were not using the internet regularly were more likely to have inadequate $\mathrm{HL}$ levels than those using the internet regularly $(\mathrm{OR}=5.5 ; 95 \% \mathrm{CI}(1.2-25.1)$; $\mathrm{p}=0.029)$. Similarly, the participants who did not search health information on the internet and had poor SE levels were more likely to have inadequate $\mathrm{HL}$ levels $(\mathrm{OR}=1.7 ; 95 \% \mathrm{CI}(1.1-2.9)$; $\mathrm{p}=0.027$ and $\mathrm{OR}=3.7 ; 95 \% \mathrm{CI}(2.6-5.2) ; \mathrm{p}=0.001$ respectively).

Table IV. Health literacy levels by sample characteristics.

\begin{tabular}{|c|c|c|c|}
\hline \multirow[b]{2}{*}{ Variables $(n=756)$} & \multicolumn{3}{|c|}{ Health Literacy } \\
\hline & $\begin{array}{l}\text { Limited health literacy } \\
\qquad \mathrm{n}(\%)\end{array}$ & $\begin{array}{l}\text { Adequate health literacy } \\
\mathrm{n}(\%)\end{array}$ & $\mathrm{p}^{*}$ value \\
\hline Age groups & & & 0.847 \\
\hline 15 years & $160(54.6)$ & $133(45.4)$ & \\
\hline 16 years & $129(55.6)$ & $103(44.4)$ & \\
\hline 17 years & $74(58.7)$ & $52(41.3)$ & \\
\hline 18 years & $61(58.1)$ & $44(41.9)$ & \\
\hline Gender & & & 0.378 \\
\hline Male & $139(53.9)$ & $119(46.1)$ & \\
\hline Female & $285(57.2)$ & $213(42.8)$ & \\
\hline Maternal education status & & & 0.001 \\
\hline No education or primary school & $176(62.2)$ & $107(37.8)$ & \\
\hline Secondary or high school & $218(55.1)$ & $178(44.9)$ & \\
\hline College/university & $30(39)$ & $47(61)$ & \\
\hline Paternal education status & & & 0.003 \\
\hline No education or primary school & & $92(52.3)$ & $84(47.7)$ \\
\hline Secondary or high School & $270(60.9)$ & $173(39.1)$ & \\
\hline College/university & $62(45.3)$ & $75(54.7)$ & \\
\hline Socioeconomic level of school district & & & 0.023 \\
\hline Low & 156 (61.9) & $96(38.1)$ & \\
\hline High & $268(53.2)$ & $236(46.8)$ & \\
\hline Internet use frequency & & & 0.005 \\
\hline Everyday & 318 (55.9) & $251(44.1)$ & \\
\hline A few days per week & $74(52.5)$ & $67(47.5)$ & \\
\hline A few days per month & $11(47.8)$ & $12(52.2)$ & \\
\hline Never & $21(91.3)$ & $2(8.7)$ & \\
\hline $\begin{array}{l}\text { Accessing health information through the } \\
\text { internet }\end{array}$ & & & 0.003 \\
\hline Yes & $353(54.1)$ & $300(45.9)$ & \\
\hline No & $71(69.6)$ & $31(30.4)$ & \\
\hline General self-efficacy level & & & 0.001 \\
\hline Poor, $<30$ & $237(73.6)$ & $85(26.4)$ & \\
\hline Good, $\geq 31$ & $187(43.1)$ & 247 (56.9) & \\
\hline
\end{tabular}

*: Pearson's chi-square test 


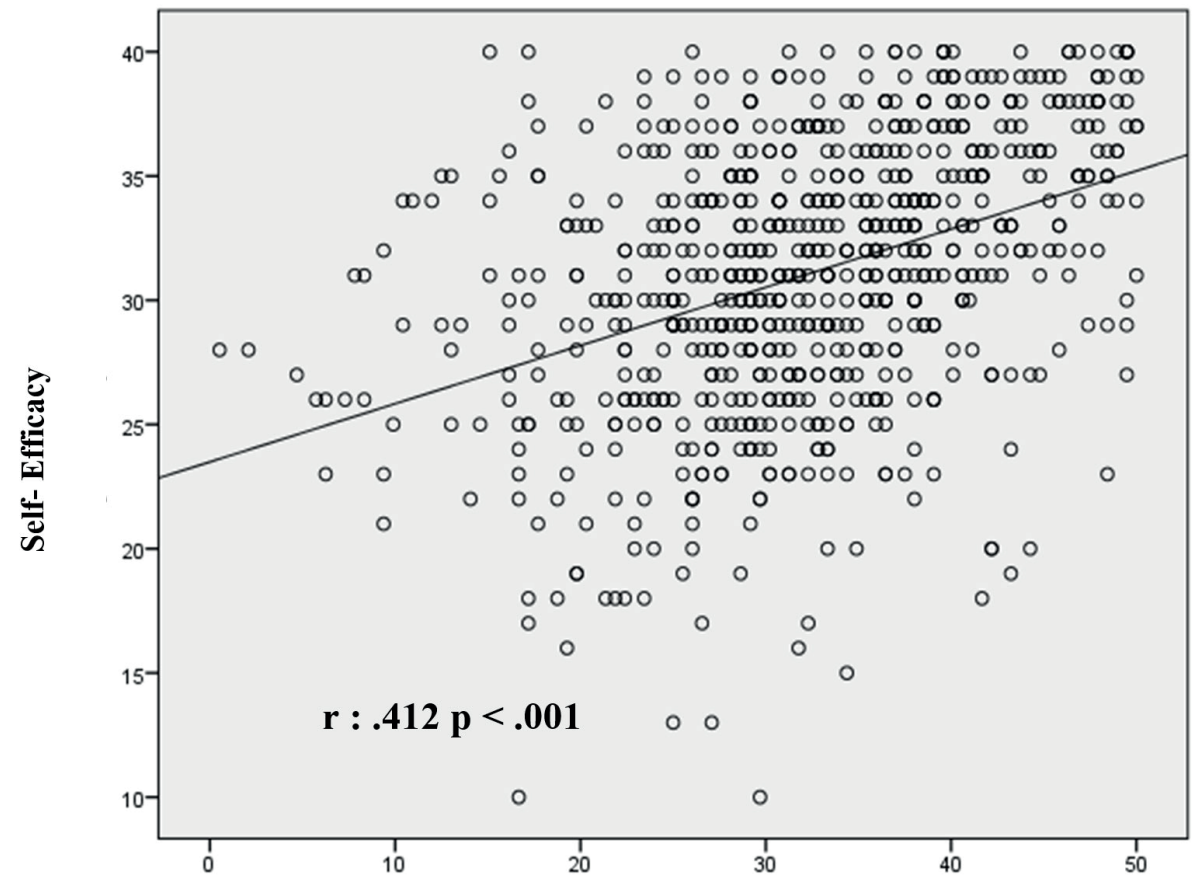

Health Literacy

Fig. 1. Correlation between Self-Efficacy and Health Literacy.

Table V. Univariate and multivariate logistic regression models testing the association between inadequate levels of health literacy and other variables.

\begin{tabular}{|c|c|c|c|c|c|c|}
\hline & \multicolumn{3}{|c|}{$\begin{array}{c}\text { Univariate Logistic Regression } \\
\text { Analysis }\end{array}$} & \multicolumn{3}{|c|}{$\begin{array}{l}\text { Multivariate Logistic } \\
\text { Regression Model }\end{array}$} \\
\hline & $\begin{array}{l}\text { Crude } \\
\text { Odds } \\
\text { Ratio }\end{array}$ & $\begin{array}{c}95 \% \\
\text { Confidence } \\
\text { Interval }\end{array}$ & p-value & $\begin{array}{c}\text { Adjusted } \\
\text { Odds } \\
\text { Ratio }\end{array}$ & $\begin{array}{c}95 \% \\
\text { Confidence } \\
\text { Interval }\end{array}$ & p-value \\
\hline \multicolumn{7}{|l|}{$\begin{array}{l}\text { Maternal education status } \\
\text { (ref: college/university) }\end{array}$} \\
\hline No education or primary school & 2.6 & $1.5-4.3$ & 0.001 & 2.6 & $1.4-4.9$ & 0.004 \\
\hline Secondary or high school & 1.9 & $1.2-3.2$ & 0.010 & 1.7 & $0.9-2.9$ & 0.077 \\
\hline \multicolumn{7}{|l|}{$\begin{array}{l}\text { Paternal education status } \\
\text { (ref: college/university) }\end{array}$} \\
\hline No education or primary school & 1.3 & $0.8-2.1$ & 0.218 & 0.7 & $0.4-1.2$ & 0.222 \\
\hline Secondary or high school & 1.9 & $1.3-2.8$ & 0.003 & 1.5 & $0.9-2.4$ & 0.066 \\
\hline $\begin{array}{l}\text { Socioeconomic level of school district: low level } \\
\text { (ref: high level) }\end{array}$ & 1.4 & $1.1-1.9$ & 0.023 & 1.3 & $0.9-1.8$ & 0.179 \\
\hline \multicolumn{7}{|l|}{ Internet use frequency (ref: Everyday) } \\
\hline A few days per week & 0.9 & $0.6-1.3$ & 0.467 & 0.9 & $0.6-1.4$ & 0.808 \\
\hline A few days per month & 0.7 & $0.3-1.7$ & 0.447 & 0.8 & $0.3-1.9$ & 0.636 \\
\hline Never & 8.3 & $1.9-35.71$ & 0.005 & 5.5 & $1.2-25.1$ & 0.029 \\
\hline $\begin{array}{l}\text { Accessing health information through the } \\
\text { internet: no (ref: yes) }\end{array}$ & 1.9 & $1.2-3.1$ & 0.004 & 1.7 & $1.1-2.9$ & 0.027 \\
\hline Poor general self-efficacy level (ref: good level) & 3.7 & $2.7-5.1$ & 0.001 & 3.7 & $2.6-5.2$ & 0.001 \\
\hline
\end{tabular}




\section{Discussion}

In this study, we assessed adolescents' health promoters. For this purpose, we first measured the HL levels of the adolescents using THLS, which was adapted from HLS-EUS and can be used for both adolescents and adults. ${ }^{28}$ HLSEUS was designed to determine the HL level of individuals living in European Union countries and included 8,000 people from eight different countries. The results were challenging and showed an insufficient literacy level at $12 \%$, with the overall rate of limited HL being calculated as $47 \%$. These results suggested that every other person in Europe required an intervention to improve HL. ${ }^{30}$ In addition, THLS was administered in two adult studies in Turkey, and a limited HL level was found in $69.2 \%$ and $60 \%$ of the participants, respectively. ${ }^{28,31}$ Data obtained from different European countries showed that the rate of limited adolescent HL levels varied between $9.3 \%$ and $47.3 \%{ }^{32-35}$ Furthermore, if we compare the adequate HL levels in our study with those evaluated in an adult THLS study in Turkey, it is clear that the adequate HL level is seen at a higher rate in adolescents than in adults. Previous generations, especially individuals of advanced age have clear disadvantages in accessing internet-based health information. There may also be some loss of HL with senility. ${ }^{36}$ When we checked the data of the previous THLS study conducted in Turkey, a limited HL level was found in $63.3 \%$ of the participants aged 25-32 years and 66\% of those aged 35-45 years. ${ }^{28}$ In our study, the rate of limited HL level was $56.1 \%$ among the adolescents. The loss ratio of HL was between 7.2 and $9.9 \%$, even in young adults in Turkey. This can be explained by inadequate health policies and HL education. Decreasing HL levels during the transition from adolescence to adulthood indicate the need for new strategies to prevent this loss. Supporting and improving adolescent HL levels may inevitably have consequences not only for adolescence but also adulthood.

It is known that HL is influenced by different factors. Wharf et al. ${ }^{37}$ suggested a social- ecological model to understand the influencers of adolescent HL. This model included intrapersonal (characteristics, values, and experiences) and interpersonal (social support, groups, and family) factors. Concerning demographics, Levin-Zamir et al. ${ }^{38}$ and Pakkari et al. ${ }^{34}$ showed a positive correlation between higher HL and female sex in adolescents. Other adolescent HL studies also showed a significant relationship of HL with age. ${ }^{39,40}$ Although some studies support the link between HL and sociodemographic factors, a systematic review of adolescent HL data according to age and sex reported inconsistent results. ${ }^{6}$ Our study also showed that sex and age were not related to the HLlevels of the adolescents. AlsoSE is considered to be one of the vital parts of intrapersonal factors, there are only a few studies in the literature reporting the relationship between HL and SE in adolescents. ${ }^{41,42}$ Nevertheless, disease-based (adult studies (such as asthma, hypertension, and type 2 diabetes mellitus) are more common and show that patients with chronic diseases require higher $\mathrm{HL}$ and $\mathrm{SE}$ levels for better disease control. ${ }^{43-46}$ We found a significant correlation between HL and general SE in healthy adolescents. Regarding the results of both adult and adolescent studies, we suggest that if higher SE levels can be achieved and maintained in adolescents, this may help increase their HL levels and ability to cope with chronic diseases in adulthood. However, further research is warranted to provide a better understanding of these aspects of adolescent HL.

It is well known that HL is highly related to the education level in adults. ${ }^{47-50}$ Moreover, research has shown a significant relationship between high parental education and adequate adolescent HL levels. ${ }^{37-39,51,52}$ This may be because parents who have higher education levels better transfer their HL skills to their children or provide them with more resources to effectively access information when needed. In the current study, we found that both parents' education status affected adolescent HL, but our logistic model showed that only 
maternal education status was truly effective in adolescents' HL. To our knowledge, this is the first study that emphasizes the relationship between maternal education status and their children's HL level. Although Levin-Zamir et al. ${ }^{37}$ showed a significant relationship between maternal education level and adolescent HL, paternal education level was not included as a parameter in their analysis. It is also known that children whose mothers' have higher education status have increased breastfeeding time and healthy nutrition habits, decreased obesity, and easy access to health services. ${ }^{53-55}$ Maternal education status affects many parameters in children's lives, and our study revealed that it also affected their HL levels.

Tylee et al. ${ }^{56}$ found that adolescents did not tend to seek any healthcare services unless their families asked them to because they feared that their confidentiality might not be protected by healthcare providers. A study designed by the OPINION research group investigated the primary sources of access to health information among the citizens of the European Union and reported that $55.7 \%$ of the individuals aged 15-24 years preferred the internet as a primary source, while only $26 \%$ of those aged 55 and over resorted to the internet for this purpose. ${ }^{57}$ Many United States studies have shown that the most searched health subjects via the internet are sexual activity, contraception, alcohol, sexually transmitted diseases, and drug use by adolescents. ${ }^{58,59}$ When we asked our participants about the most searched health-related subjects via the internet, we observed that this was the most popular question and received 2,879 responses. Contrary to the studies conducted in the United States, their most preferred subjects were less selected ones among the Turkish adolescents. Moreover, Ghaddar et al. found that the HL level was significantly higher in adolescents using https://medlineplus.gov/ (United States National Library of Medicine). ${ }^{41}$ Today, increased internet use in the presence of health problems suggests that the internet may be a suitable tool for promoting HL in adolescents who use this technology very actively. ${ }^{60}$ In addition, in our study, using the internet more frequently and accessing health information through the internet were determined to be related to high HL levels in adolescents. Thus, although cultural differences affect adolescents' interest in health-related subjects, the current study confirmed that the internet was one of the most preferred and reliable sources of health information for adolescents.

Our study had certain limitations. Although the validity and reliability analyses of the HL and SE scales were previously conducted, there is only limited research on the adolescent population and these scales were mainly designed for adults. Further studies should be conducted to support the use of these scales in the adolescent population. In addition, although most adolescents are students, some are employed and have their own families and children. Further studies should be planned to reach wider adolescent populations from different environments.

In line with our results, our recommendations are given below.

Further studies should be planned to measure and promote adolescent HL. HL should not be considered an independent issue, and studies should consider the relationship between HL and SE. Considering that adolescents are active internet users and use the internet as frequently as consulting doctors to seek healthrelated issues, the internet can be used as a powerful tool for improving HL in adolescents. Reliable sources suitable to the culture of the living environment should be provided under the supervision of healthcare specialists. Furthermore, one of the most critical findings of this study was the significant relationship between maternal education status and the adolescents' HL levels; thus, it is essential to support girls' education, especially in Turkey. This will not only support their future but also contribute to the protection and promotion of health in future generations. 


\section{Ethical approval}

The study was approved by the local ethics committee of Keçiören Research and Training Hospital (approval reference number: 2012KAEK-15/1606).

\section{Author contribution}

The authors confirm contribution to the paper as follows: study conception and design: DC, FNAC, ZA, SÖ; data collection: DC, FNAC; analysis and interpretation of results: FNAC, SÖ; draft manuscript preparation: DC, ZA. All authors reviewed the results and approved the final version of the manuscript.

\section{Source of funding}

The authors declare the study received no funding.

\section{Conflict of interest}

The authors declare that there is no conflict of interest.

\section{REFERENCES}

1. Christie D, Viner R. Adolescent development. BMJ 2005; 330: 301-304. https://doi.org/10.1136/ bmj.330.7486.301

2. Kleinert S. Adolescent health: an opportunity not to be missed. Lancet 2007; 369: 1057-1058. https://doi. org/10.1016/S0140-6736(07)60374-2

3. Shone LP, King JP, Doane C, Wilson KM, Wolf MS. Misunderstanding and potential unintended misuse of acetaminophen among adolescents and young adults. J Health Commun 2011; 16: 256-267. https:// doi.org/10.1080/10810730.2011.604384

4. Blakemore SJ, Robbins T. Decision-making in the adolescent brain. Nat Neurosci 2012; 15: 1184-1191. https://doi.org/10.1038/nn.3177

5. Alwan A, Maclean DR, Riley LM, et al. Monitoring and surveillance of chronic non-communicable diseases: progress and capacity in high-burden countries. Lancet 2010; 376: 1861-1868. https://doi. org/10.1016/S0140-6736(10)61853-3
6. Fleary SA, Joseph P, Pappagianopoulos JE. Adolescent health literacy and health behaviors: a systematic review. J Adolesc 2018; 62: 116-127. https://doi.org/10.1016/j.adolescence.2017.11.010

7. Sorensen K, Van den BrouckeS, Fullam J, et al. Health literacy and public health: a systematic review and integration of definitions and models. BMC Public Health 2012; 12: 80. https://doi.org/10.1186/14712458-12-80

8. Institute of Medicine (US) Committee on Health Literacy. Health Literacy: A Prescription to End Confusion. Nielsen-Bohlman L, Panzer AM, Kindig DA (eds). Washington (DC): National Academies Press, 2004.

9. Sharif I, Blank AE. Relationship between child health literacy and body mass index in overweight children. Patient Educ Couns 2010; 79: 43-48. https:// doi.org/10.1016/j.pec.2009.07.035

10. Humensky JL. Are adolescents with high socioeconomic status more likely to engage in alcohol and illicit drug use in early adulthood? Subst Abuse Treat Prev Policy 2010; 5: 19. https:// doi.org/10.1186/1747-597X-5-19

11. Osborn CY, Cavanaugh K, Wallston KA, Rothman RL. Self-efficacy links health literacy and numeracy to glycemic control. J Health Commun 2010; 15: 146158. https://doi.org/10.1080/10810730.2010.499980

12. Bandura, A. Self-efficacy: the exercise of control New York: W. H. Freeman, 1997.

13. Stuifbergen AK, Seraphine A, Roberts G. An explanatory model of health promotion and quality of life in chronic disabling conditions. Nursing Research. 2000; 49: 122-129. https://doi. org/10.1097/00006199-200005000-00002

14. Apter AJ, Wang X, Bogen D, et al. Linking numeracy and asthma-related quality of life. Patient Educ Couns 2009; 75: 386-391. https://doi.org/10.1016/j. pec.2009.01.003

15. Nickel F, Schmidt L, Bruckner T, Müller-Stich BP, Fischer L. Influence of bariatric surgery on quality of life, body image, and general self-efficacy within 6 and 24 months-a prospective cohort study. Surg Obes Relat Dis 2017; 13: 313-319. https://doi. org/10.1016/j.soard.2016.08.017

16. Guntzviller LM, King AJ, Jensen JD, Davis LA. Selfefficacy, health literacy, and nutrition and exercise behaviors in a low-income, hispanic population. J Immigr Minor Health 2017; 19: 489-493. https:/doi. org/10.1007/s10903-016-0384-4 
17. Punamäki RL, Wallenius $\mathrm{M}$, Nygård $\mathrm{CH}$, Saarni L, Rimpelä A. Use of information and communication technology (ICT) and perceived health in adolescence: the role of sleeping habits and wakingtime tiredness. J Adolesc 2007; 30: 569-585. https:// doi.org/10.1016/j.adolescence.2006.07.004

18. Kim SU, Syn SY. Research trends in teens' health information behaviour: a review of the literature. Health Info Libr J 2014; 31: 4-19. https://doi. org/10.1111/hir.12057

19. Borzekowski DL, Fobil JN, Asante KO. Online access by adolescents in Accra: Ghanaian teens' use of the internet for health information. Dev Psychol 2006; 42: 450-458. https://doi.org/10.1037/0012-1649.42.3.450

20. Neumark Y, Lopez-Quintero C, Feldman BS. Online health information seeking among Jewish and Arab adolescents in Israel: results from a national school survey. J Health Commun 2013; 18: 1097-1115. https://doi.org/10.1080/10810730.2013.778360

21. Jiménez-Pernett J, de Labry-Lima AO, BermúdezTamayo C, García-Gutiérrez JF, del Carmen Salcedo-Sánchez M. Use of the internet as a source of health information by Spanish adolescents. BMC Med Inform Decis Mak. 2010; 10: 6. https://doi. org/10.1186/1472-6947-10-6

22. Wartella E, Rideout V, Zupancic H, Beaudoin-Ryan L, Lauricella A. Teens, health, and technology: a national survey. Northwestern University, 2015. Available at: https://cmhd.northwestern.edu/wpcontent/uploads/2015/05/1886_1_SOC_ConfReport_ TeensHealthTech_051115.pdf

23. Hansen DL, Derry HA, Resnick PJ, Richardson CR. Adolescents searching for health information on the internet: an observational study. J Med Internet Res 2003; 17: 25. https://doi.org/10.2196/jmir.5.4.e25

24. Mutlu MK, Beşkaya A, Taş R, et al. Ankara'nın kentsel yoksulluk haritası. Ankara: Turgut Özal Üniversitesi Yayınları, 2012.

25. Fadare J, Olamoyegun M, Gbadegesin BA. Medication adherence and direct treatment cost among diabetes patients attending a tertiary healthcare facility in Ogbomosho, Nigeria. Malawi Med J 2015; 27: 65-70. https://doi.org/10.4314/mmj. v27i2.7

26. Dean AG, Sullivan KM, Soe MM. OpenEpi: Open Source Epidemiologic Statistics for Public Health, Version. www.OpenEpi.com, Accessed 12/07/2021 (OpenEpi: Sample Size for Sample Size for \% Frequency in a Population https://www.openepi. com/SampleSize/SSPropor.htm
27. Israel GD. Determining sample size. University of Florida, IFAS Extension, 1992. Available at: https://www.tarleton.edu/academicassessment/ documents/samplesize.pdf (Accessed on July 12, 2021)

28. Okyay P, Abacıgil F. Türkiye Sağlık Okuryazarlığı Ölçekleri Güvenilirlik ve Geçerlilik Çalışması. Ankara: Sağlık Bakanlığı Yayınları, 2016.

29. Aypay A. Genel Öz Yeterlik Ölçeği'nin (GÖYÖ) Türkçe'ye uyarlama çalışması. İnönü Üniversitesi Eğitim Fakültesi Dergisi 2010; 11: 113-132.

30. Sørensen K, Pelikan JM, Röthlin F, et al. Health literacy in Europe: comparative results of the European health literacy survey (HLS-EU). Eur J Public Health 2015; 25: 1053-1058. https://doi. org/10.1093/eurpub/ckv043

31. Cangöz K, Savcı Ö, Sırtbaşı S, et al. Ankara il merkezinde bazı aile sağlığı merkezlerine başvuran 18 yaş üstü bireylere yönelik sağlık okuryazarlığı ve genel düzeylerinin değerlendirilmesi. Ankara: 2017.

32. Loer AKM, Domanska OM, Stock C, Jordan S. Subjective generic health literacy and its associated factors among adolescents: results of a populationbased online survey in Germany. Int J Environ Res Public Health 2020; 17: 8682. https://doi.org/10.3390/ ijerph17228682

33. Sukys S, Trinkuniene L, Tilindiene I. Subjective health literacy among school-aged children: first evidence from Lithuania. Int J Environ Res Public Health 2019; 16: 3397. https://doi.org/10.3390/ ijerph16183397

34. Paakkari O, Torppa M, Villberg J, Kannas L, Paakkari L. Subjective health literacy among school-aged children. Health Educ 2018; 118: 182-195. https://doi. org/10.1108/HE-02-2017-0014

35. Berens EM, Vogt D, Messer M, Hurrelmann K, Schaeffer D. Health literacy among different age groups in Germany: results of a cross-sectional survey. BMC Public Health 2016; 16: 1151. https:// doi.org/10.1186/s12889-016-3810-6

36. Javadzade SH, Sharifirad G, Radjati F, Mostafavi F, Reisi M, Hasanzade A. Relationship between health literacy, health status, and healthy behaviors among older adults in Isfahan, Iran. J Educ Health Promot 2012; 1: 31. https://doi.org/10.4103/2277-9531.100160

37. Wharf Higgins J, Begoray D, MacDonald M. A social ecological conceptual framework for understanding adolescent health literacy in the health education classroom. Am J Community Psychol 2009; 44: 350362. https://doi.org/10.1007/s10464-009-9270-8 
38. Levin-Zamir D, Lemish D, Gofin R. Media Health Literacy (MHL): development and measurement of the concept among adolescents. Health Educ Res 2011; 26: 323-335. https://doi.org/10.1093/her/cyr007

39. Chisolm DJ, Manganello JA, Kelleher KJ, Marshal MP. Health literacy, alcohol expectancies, and alcohol use behaviors in teens. Patient Educ Couns 2014; 97: 291-296. https://doi.org/10.1016/j. pec.2014.07.019

40. Primack BA, Gold MA, Land SR, Fine MJ. Association of cigarette smoking and media literacy about smoking among adolescents. J Adolesc Health 2006; 39: 465-472. https://doi.org/10.1016/j. jadohealth.2006.05.011

41. Ghaddar SF, Valerio MA, Garcia CM, Hansen L. Adolescent health literacy: the importance of credible sources for online health information. J Sch Health 2012; 82: 28-36. https://doi.org/10.1111/j.17461561.2011.00664.x

42. Guo S, Yu X, Davis E, Riggs E, Naccarella L. Adolescent health literacy in Beijing and Melbourne: A cross-cultural comparison. Int J Environ Res Public Health 2020; 17: 1242. https://doi.org/10.3390/ ijerph17041242

43. Wang C, Lang J, Xuan L, Li X, Zhang L. The effect of health literacy and self-management efficacy on the health-related quality of life of hypertensive patients in a western rural area of China: a cross-sectional study. Int J Equity Health 2017; 16: 58. https://doi. org/10.1186/s12939-017-0551-9

44. Lee SY, Tsai TI, Tsai YW, Kuo KN. Health literacy, health status, and healthcare utilization of Taiwanese adults: results from a national survey. BMC Public Health 2010; 10: 614. https://doi.org/10.1186/14712458-10-614

45. Bodenheimer T, Lorig K, Holman H, Grumbach K. Patient self-management of chronic disease in primary care. Jama 2002; 288: 2469-2475. https://doi. org/10.1001/jama.288.19.2469

46. Wolf MS, Davis TC, Osborn CY, Skripkauskas S, Bennett CL, Makoul G. Literacy, self-efficacy, and HIV medication adherence. Patient Educ Couns 2007; 65: 253-260. https://doi.org/10.1016/j.pec.2006.08.006

47. Rudd RE. Health literacy skills of U.S. adults. Am J Health Behav 2007; 3: 8-18. https://doi.org/10.5993/ AJHB.31.s1.3

48. Keim-Malpass J, Letzkus LC, Kennedy C. Parent/ caregiver health literacy among children with special health care needs: a systematic review of the literature. BMC Pediatr 2015; 15: 92. https://doi. org/10.1186/s12887-015-0412-x
49. Paasche-Orlow MK, Parker RM, Gazmararian JA, Nielsen-Bohlman LT, Rudd RR. The prevalence of limited health literacy. J Gen Intern Med 2005; 20: 175 184. https://doi.org/10.1111/j.1525-1497.2005.40245.x

50. Howard DH, Sentell T, Gazmararian JA. Impact of health literacy on socioeconomic and racial differences in health in an elderly population. J Gen Intern Med 2006; 21: 857-861. https://doi.org/10.1111/ j.1525-1497.2006.00530.x

51. Stella MY, Bellamy HA, Schwalberg RH, Drum MA Factors associated with use of preventive dental and health services among US adolescents. J Adolesc Health 2001; 29: 395-405. https://doi.org/10.1016/ S1054-139X(01)00252-X

52. Chang FC, Chiu $\mathrm{CH}$, Chen $\mathrm{PH}$, et al. Relationship between parental and adolescent ehealth literacy and online health information seeking in Taiwan. Cyberpsychol Behav Soc Netw 2015; 18: 618-624. https://doi.org/10.1089/cyber.2015.0110

53. Block SA. Maternal nutrition knowledge versus schooling as determinants of child micronutrient status. Oxf Econ Pap 2007; 59: 330-353. https://doi. org/10.1093/oep/gpm001

54. Burchi F. Child nutrition in Mozambique in 2003: the role of mother's schooling and nutrition knowledge. Econ Hum Biol 2010; 8: 331-345. https://doi. org/10.1016/j.ehb.2010.05.010

55. Seid AK. Health and nutritional status of children in Ethiopia: do maternal characteristics matter? J Biosoc Sci 2013; 45: 187-204. https://doi.org/10.1017/ S0021932012000442

56. Tylee A, Haller DM, Graham T, Churchill R, Sanci LA. Youth-friendly primary-care services: how are we doing and what more needs to be done? Lancet 2007; 369: 1565-1573. https://doi.org/10.1016/S01406736(07)60371-7

57. Spadaro R. European Union citizens and sources of information about health. European Union Research Group, 2003.

58. Rideout V. Generation Rx.com. What are young people really doing online?. Mark Health Serv 2002; 22: 26-30.

59. Borzekowski DL, Rickert VI. Adolescent cybersurfing for health information: a new resource that crosses barriers. Arch Pediatr Adolesc Med 2001; 155: 813817. https://doi.org/10.1001/archpedi.155.7.813

60. Moreno MA, Ralston JD, Grossman DC. Adolescent access to online health services: perils and promise. J Adolesc Health 2009; 44: 244-251. https://doi. org/10.1016/j.jadohealth.2008.07.015 